\title{
Resistance of Botryosphaeria dothidea from Pistachio to Iprodione
}

\author{
Zhonghua Ma, Yong Luo, and Themis J. Michailides, Department of Plant Pathology, University of California, \\ Davis, and Kearney Agricultural Center, Parlier, CA 93648
}

\begin{abstract}
Ma, Z., Luo, Y., and Michailides, T. J. 2001. Resistance of Botryosphaeria dothidea from pistachio to iprodione. Plant Dis. 85:183-188.

Out of 79 field-collected isolates of Botryosphaeria dothidea, causal agent of panicle and shoot blight of California pistachio, 1 had low resistance to the dicarboximide fungicide iprodione (effective fungicide concentration to inhibit $50 \%$ of mycelial growth $\left[\mathrm{EC}_{50}\right]=2.726 \mu \mathrm{g} / \mathrm{ml}$ ), whereas all the other isolates were sensitive $\left(\mathrm{EC}_{50}<1 \mu \mathrm{g} / \mathrm{ml}\right)$. B. dothidea isolates readily developed resistance to iprodione in vitro. Furthermore, these in vitro-derived iprodioneresistant (IR) isolates retained high virulence on pistachio. The $\mathrm{EC}_{50}$ values for these IR isolates were greater than $25 \mu \mathrm{g} / \mathrm{ml}$, whereas the $\mathrm{EC}_{50}$ values for the original wild-type counterparts were less than $1 \mu \mathrm{g} / \mathrm{ml}$. Iprodione resistance significantly declined when these IR isolates were propagated on pistachio leaves in the absence of the fungicide. IR isolates also were resistant to vinclozolin, another dicarboximide fungicide, but sensitive to tebuconazole and benomyl. IR isolates showed an increase in osmotic sensitivity on media amended with $\mathrm{NaCl}$. Applications of iprodione at $500 \mu \mathrm{g} / \mathrm{ml}$, which is effective against naturally sensitive isolates, failed to control disease caused by IR isolates in both the laboratory and greenhouse. The results indicate that, although naturally occurring IR isolates of $B$. dothidea may be rare in California pistachio orchards, the fungus readily develops resistance to iprodione in vitro and, more importantly, retains high levels of virulence on pistachio.
\end{abstract}

Additional keywords: Dothiorella sp., fungicide resistance, Rovral

Botryosphaeria panicle and shoot blight, caused by Botryosphaeria dothidea (imperfect stage Dothiorella sp.), has recently become an important disease of pistachio (Pistacia vera L.) throughout California. Initially, only pistachios grown in the Sacramento Valley were affected by this pathogen; however, by the late 1990s, severe disease outbreaks significantly reduced both yield and fruit quality in orchards of the Central San Joaquin Valley (19). Recently, samples of blighted pistachio shoots and clusters collected from the southernmost part of Kern County were also found to have pycnidia of $B$. dothidea (20). Due to the rapid spread of this pathogen throughout California, Botryosphaeria panicle and shoot blight is now considered the single greatest threat to the California pistachio industry.

Control of Botryosphaeria blight becomes difficult once this disease has been established in orchards. A number of fungicides have been tested and proved to provide only marginal control. The dicarboximide fungicide iprodione (Rovral; Rhône Poulenc Ag. Co., Lyon, France), however, is effective for controlling

Corresponding author: T. J. Michailides

E-mail: Themis@uckac.edu

Accepted for publication 25 October 2000.

Publication no. D-2000-1130-01R

(C) 2001 The American Phytopathological Society
Botryosphaeria panicle and shoot blight of pistachio $(16,17)$. Isolates resistant to iprodione were rarely observed in nature after the introduction of this fungicide in the mid 1970s. However, by the early 1980s, resistant isolates of Botrytis cinerea were reported from several crops (13). Loss of efficacy of dicarboximides due to resistance has been reported for Botrytis cinerea from vineyards in New Zealand (21), greenhouse-grown cucumbers in Israel (27), and strawberry fields in England (11). Furthermore, many fungal plant pathogens, such as Alternaria alternata (2,15), Sclerotinia minor $(3,10,23)$, and $S$. homeocarpa (5), were reported to readily develop iprodione-resistant (IR) variants in the laboratory. After several years of intensive use of dicarboximide fungicides, IR fungal isolates have also been reported from the field $(4,5,24)$.

The fitness of dicarboximide-resistant fungal isolates varies significantly (25). Some dicarboximide-resistant isolates have been reported to show lower virulence $(5,8,14,26)$ and higher osmotic sensitivity $(1,7,12)$ than their wild-type counterparts. However, high fitness in dicarboximideresistant isolates has also been reported $(3,8,14)$. A study of the fitness of IR $B$. dothidea isolates might provide information useful in prolonging the efficacy of iprodione in controlling Botryosphaeria blight on California pistachio. The objectives of this study were to (i) survey naturally occurring $B$. dothidea isolates from
California pistachio orchards for sensitivity to iprodione; (ii) select IR isolates of $B$. dothidea in the laboratory and test the stability of resistance, osmotic sensitivity, and virulence for these isolates; (iii) test the efficacy of iprodione for controlling Botryosphaeria blight caused by IR isolates; and (iv) test for cross-resistance with vinclozolin, tebuconazole, and benomyl.

\section{MATERIALS AND METHODS}

Survey of $B$. dothidea sensitivity to iprodione. Seventy-nine isolates, collected from eight California pistachio orchards from 1997 to 1999 , were used to assess the sensitivity of $B$. dothidea to iprodione. Tissue plugs $(0.5$ by $0.5 \mathrm{~cm})$ cut from diseased leaves and fruit were surface sterilized by soaking in $0.05 \%$ sodium hypochlorite (10\% commercial bleach; Western Family Foods, Inc., Portland, OR) for 3 min and rinsed three times with sterilized deionized water. To isolate the fungus, tissue plugs were placed on acidified (2.5 $\mathrm{ml}$ of $25 \%$ [vol/vol] lactic acid per liter) Difco potato dextrose agar (APDA). Isolation of $B$. dothidea was confirmed after the petri dishes were incubated at $30^{\circ} \mathrm{C}$ for 5 days. Isolates collected in 1997 and 1998 were routinely stored on grade 40 silica gel (Davison Chemical, Baltimore) at $4^{\circ} \mathrm{C}$, whereas isolates collected in 1999 were stored in APDA slants at $9^{\circ} \mathrm{C}$.

Technical iprodione (a.i. 95\%) was dissolved in acetone to the concentration of $10 \mu \mathrm{g} / \mu \mathrm{l}$ and added to the APDA medium to produce five standard concentrations: 0 , $0.25,0.5,1.0$, and $2.0 \mu \mathrm{g}$ of iprodione per milliliter of medium. A 5-mm mycelial plug was cut from the edge of a 3-day-old colony and placed on the center of an APDA dish amended with each of the five iprodione concentrations. Two replicates for each concentration were used. The colony diameter was measured with the original mycelial plug diameter $(5 \mathrm{~mm})$ subtracted from this measurement after the dishes were incubated at $30^{\circ} \mathrm{C}$ for 3 days. For each isolate, a linear regression of percent inhibition related to control of mycelial growth versus the $\log _{10}$ transformation for each of the five iprodione concentrations was obtained. The effective concentration to inhibit $50 \%$ of mycelial growth $\left(\mathrm{EC}_{50}\right)$ of each isolate was calculated using a linear equation. Frequencies of $\mathrm{EC}_{50}$ for the 79 tested isolates were calculated using the procedure FREQ of SAS (version 7.0; SAS Institute, Cary, NC) and the distribution of $\mathrm{EC}_{50}$ for these isolates was determined. 
Induction of iprodione-resistant (IR) isolates in vitro. IR isolates were selected after growing wild-type isolates on APDA amended with iprodione at 50, 400, and $1,000 \mu \mathrm{g} / \mathrm{ml}$ of medium from the first through the third generation, respectively. For each generation, dishes were incubated at $30^{\circ} \mathrm{C}$ for 20 days. The $\mathrm{EC}_{50}$ value for each isolate of the third generation was determined on APDA amended with iprodione at $0,3.125,6.25,12.5,25,50$, and $100 \mu \mathrm{g} / \mathrm{ml}$ of medium. After three generations, six IR isolates, designated $1 \mathrm{R}, 3 \mathrm{R}$, $4 R, 9 R, 11 R$, and 15R, were obtained from nine wild-type isolates, each of which originated from a corresponding wild-type iprodione-sensitive (IS) isolate $1 \mathrm{~S}, 3 \mathrm{~S}, 4 \mathrm{~S}$, 9S, 11S, and 15S. These six IR isolates and their corresponding IS isolates were used in the following studies. cal grade vinclozolin (a.i. 98.8\%; BASF Agricultural Chemical, Inc., Research Triangle Park, NC) and benomyl (a.i. 95\%; Du Pont, Inc., Wilmington, DE) were dissolved in acetone and adjusted to 80 and 10 $\mu \mathrm{g} / \mu \mathrm{l}$, respectively. Technical tebuconazole (a.i. 97.5\%; Bayer AG, Inc., Bayerwerk, Germany) was dissolved in ethanol and adjusted to $10 \mu \mathrm{g} / \mu \mathrm{l}$. APDA media were amended with each of the fungicides at the following concentrations: vinclozolin at 0 , $0.125,0.25,0.5,1.0,12.5,25,50$, and 100 $\mu \mathrm{g} / \mathrm{ml}$; benomyl at $0,0.1,0.2,0.4$, and 0.8 $\mu \mathrm{g} / \mathrm{ml}$; and tebuconazole at $0,0.125,0.25$, 0.5 , and $1.0 \mu \mathrm{g} / \mathrm{ml}$. Two replicates of each fungicide concentration were used. A 5$\mathrm{mm}$ mycelial plug for each IR or IS isolate of $B$. dothidea was taken from the edge of a 3-day-old colony and transferred onto the APDA dish amended with each concentration of the above fungicides. Petri dishes were incubated at $30^{\circ} \mathrm{C}$ for 3 days and the diameter for each colony was measured. The experiment was performed twice. The $\mathrm{EC}_{50}$ was calculated as described above and, because the two experiments did not differ statistically $(P>$
Detection of cross-resistance. Techni-

0.05), the average $\mathrm{EC}_{50}$ values from two experiments for each isolate were used in the data analysis. In order to compare the cross-resistance between fungicides, the $\mathrm{EC}_{50}$ for IR and IS isolates to iprodione were plotted versus the $\mathrm{EC}_{50}$ of these isolates to vinclozolin, tebuconazole, or benomyl, and correlation was tested using the procedure CORR of SAS (version 7.0, SAS Institute).

Measurement of osmotic sensitivity. For each IR or IS isolate of $B$. dothidea, a 5-mm mycelial plug was taken from an actively growing colony and transferred to an APDA dish amended with 1, 2, 4, 6, or $8 \%$ (wt/vol) $\mathrm{NaCl}$, respectively. APDA dishes without $\mathrm{NaCl}$ were used as controls. Two replicates for each $\mathrm{NaCl}$ concentration were used. Dishes were incubated at $30^{\circ} \mathrm{C}$ for 3 days, and the colony diameter was measured for each dish. The percentage of the mycelial radial growth inhibition (RGI) was calculated using the formula $\mathrm{RGI}=(\mathrm{C}$ $-\mathrm{N}) / \mathrm{C}$, where $\mathrm{C}$ is colony diameter of non$\mathrm{NaCl}$ control and $\mathrm{N}$ is that for an $\mathrm{NaCl}$ treatment. The experiment was performed twice and the data were analyzed using analysis of variance (ANOVA) of SAS (version 7.0, SAS Institute).

Resistance stability of IR isolates following mycelial propagation. Pistachio leaves in the greenhouse were wounded and inoculated with mycelial plugs taken from each of the six IR isolates. Four leaves per IR isolate were used. Two weeks after inoculation, a small (5-by-5$\mathrm{mm}$ ) diseased tissue plug was removed from the lesion edge for each inoculated leaf and surface sterilized in $0.05 \%$ sodium hypochlorite for $3 \mathrm{~min}$. Four diseased tissue plugs for each isolate were placed in a single dish and incubated at $30^{\circ} \mathrm{C}$ for 5 days. A mycelium plug, $5 \mathrm{~mm}$ in diameter, taken from the center of each dish, was then transferred into a fresh dish and incubated at $30^{\circ} \mathrm{C}$ for 3 days. Four mycelial plugs were taken from the edge of each colony for inoculation onto four pistachio

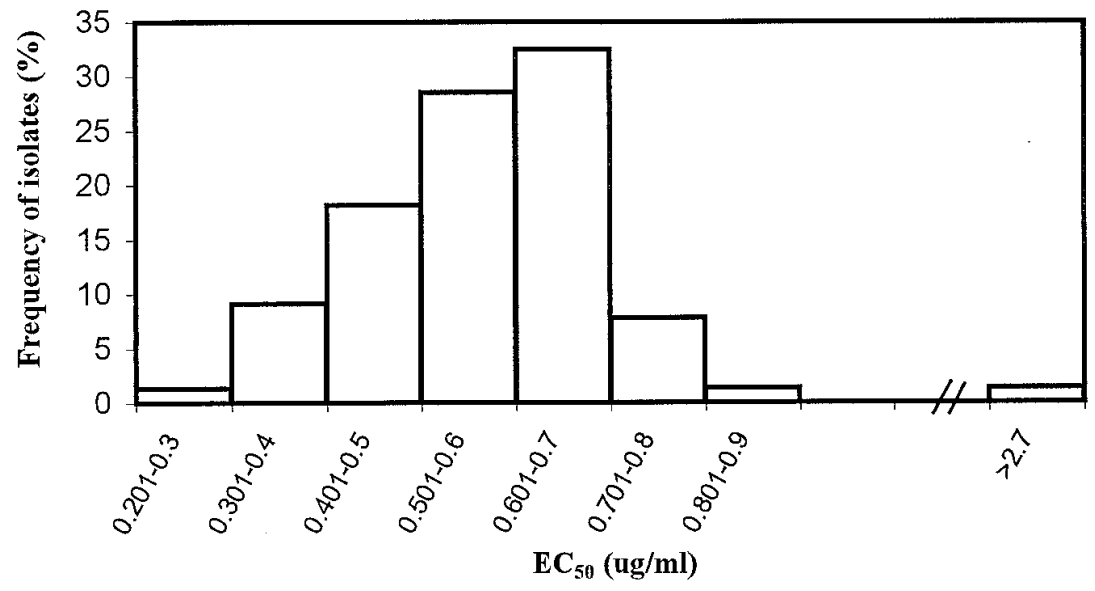

Fig. 1. Frequency distribution of effective concentration $\left(\mathrm{EC}_{50}\right)$ of iprodione to inhibit $50 \%$ of mycelial growth for 79 isolates of Botryosphaeria dothidea collected from eight different pistachio orchards throughout California during 1997 through 1999. leaves in the greenhouse again, and the dish was stored at $9^{\circ} \mathrm{C}$ for detection of $\mathrm{EC}_{50}$ of each IR isolate generation. After four successive generations of inoculation using the same method as described above, the $\mathrm{EC}_{50}$ to iprodione for each generation was determined on APDA media amended with iprodione at $0,1.56,3.125,6.25,12.5$, 25.0, 50.0, and $100 \mu \mathrm{g} / \mathrm{ml}$. The least significant difference (LSD) of SAS (version 7.0, SAS Institute) was used to compare $\mathrm{EC}_{50}$ among each generation for each IR isolate.

Resistance stability of IR isolate $9 R$ following spore propagation. Leaves detached from greenhouse-grown pistachio trees were surface sterilized as described above. Each leaf was inoculated with a mycelial plug of IR isolate 9R. The inoculated leaves were incubated at room temperature $\left(25 \pm 2^{\circ} \mathrm{C}\right)$ in a humidified plastic container for 20 days. Nine single-conidial isolates were obtained from pycnidia produced on these leaves. The $\mathrm{EC}_{50}$ value for each single-conidial isolate to iprodione was determined using the method described above and the $\mathrm{EC}_{50}$ values for single-conidial isolates were compared with the $\mathrm{EC}_{50}$ for the original isolate $9 \mathrm{R}$ using the LSD of SAS.

Efficacy of iprodione in controlling disease caused by IR and IS isolates. In laboratory tests, fully expanded detached pistachio leaves were surface sterilized as previously described and sprayed with iprodione at $500 \mu \mathrm{g} / \mathrm{ml}$ (the manufacturer's recommended field dosage) with a handheld sprayer. Leaves sprayed with water were used as the nontreatment controls. After drying, each leaf was inoculated with a 3-mm mycelial plug from each IR isolate (1R, 3R, 4R, 9R, 11R, and 15R) and each IS isolate (1S, $3 \mathrm{~S}, 4 \mathrm{~S}, 9 \mathrm{~S}, 11 \mathrm{~S}$, and $15 \mathrm{~S}$ ). Two replicates (10 leaves/replicate) for each isolate were used, and the leaves incubated at $30^{\circ} \mathrm{C}$ in humidified plastic containers for 4 days. The lesion length for each leaf was recorded. The efficacy of iprodione (EI) in controlling disease was calculated using the following formula: EI $=(\mathrm{LC}-\mathrm{LT}) / \mathrm{LC}$, where $\mathrm{LC}$ is the average lesion length (in centimeters) from 10 nontreated control leaves and LT is that from 10 iprodione-treated leaves. The experiment was performed twice and data analyzed using ANOVA of SAS to determine the significant differences in EI between IR and IS sensitive isolates.

In greenhouse tests, 1 day prior to greenhouse inoculations, potted pistachio trees, about $2 \mathrm{~m}$ in height, were each sprayed with $100 \mathrm{ml}$ of iprodione at 500 $\mu \mathrm{g} / \mathrm{ml}$ using a hand sprayer. Trees sprayed with water alone were used as the noniprodione control. Each of three trees was inoculated with the IR isolates (1R, 3R, 4R, 9R, 11R, and 15R), the low resistance (LR) isolate L21, or the IS isolates $(1 \mathrm{~S}, 3 \mathrm{~S}, 4 \mathrm{~S}$, $9 \mathrm{~S}, 11 \mathrm{~S}$, and $15 \mathrm{~S})$. For fungal inoculation, mycelial fragments were washed from 7 - 
day-old colonies, ground in a blender, and filtered through two layers of sterile cheesecloth. The suspension was adjusted to 20,000 mycelial fragments per milliliter by measuring concentrations with a hemacytometer and used directly for inoculations. Each inoculated tree was covered with a plastic bag for $12 \mathrm{~h}$ to maintain high humidity, then placed in the greenhouse $\left(25 \pm 4^{\circ} \mathrm{C}\right)$ for 15 days and assessed for disease severity. The following system was used for severity assessment: $0=$ leaves without lesions, $1=$ lesion area less than one-fourth of the leaf area, 2 = lesion area between one-fourth and one-half of the leaf area, $3=$ lesion area between one-half and three-fourths of the leaf area, and $4=$ lesion area $>$ three-fourths of the leaf area. The disease index $(D I)$ for each tree was calculated using the formula

$$
D I=\left(\sum_{i=0}^{4} N_{i} * i\right) / \sum_{i=0}^{4} N_{i}
$$

where $i$ is severity ( 0 to 4$)$ and $N_{i}$ is the number of leaves with the severity of $i$.

The EI was calculated using the following formula: $E I=(D I C-D I T) / D I C$, where $D I C$ is $D I$ of noniprodione control and DIT is $D I$ of an iprodione treatment. The experiment was performed twice and results were averaged because the two experiments did not differ statistically $(P>0.05)$.

\section{RESULTS}

Survey for iprodione resistance. Among 79 field-collected B. dothidea isolates tested for sensitivity to the dicarboximide fungicide iprodione, only the L21 isolate showed low resistance to iprodione. The $\mathrm{EC}_{50}$ of 78 California pistachio isolates of $B$. dothidea ranged from 0.20 to $0.90 \mu \mathrm{g} / \mathrm{ml}$, whereas the $\mathrm{EC}_{50}$ for isolate L21 was $2.726 \mu \mathrm{g} / \mathrm{ml}$ (Fig. 1).

Induction of IR isolates. After 5 days of incubation, none of nine isolates grew on APDA amended with iprodione at 50 $\mu \mathrm{g} / \mathrm{ml}$. However, six of nine $B$. dothidea isolates showed some degree of resistance to the fungicide after 20 days of incubation. After successive selection for three generations on iprodione-amended media, these six isolates grew slowly on APDA amended with iprodione at $1,000 \mu \mathrm{g} / \mathrm{ml}$. The $\mathrm{EC}_{50}$ values for these six isolates were $>25 \mu \mathrm{g} / \mathrm{ml}$ and were considered IR isolates, whereas the $\mathrm{EC}_{50}$ values for wild-type isolates $1 \mathrm{~S}, 3 \mathrm{~S}, 4 \mathrm{~S}, 9 \mathrm{~S}, 11 \mathrm{~S}$, and $15 \mathrm{~S}$ were $<1 \mu \mathrm{g} / \mathrm{ml}$ (Table 1 ). The IR isolates were designated $1 \mathrm{R}, 3 \mathrm{R}, 4 \mathrm{R}, 9 \mathrm{R}$, $11 \mathrm{R}$, and $15 \mathrm{R}$.

Cross-resistance. All six IR isolates also showed resistance to another dicarboximide fungicide, vinclozolin. The $\mathrm{EC}_{50}$ values for these IR isolates to vinclozolin were $>50 \mu \mathrm{g} / \mathrm{ml}$, compared with the original wild-type isolates that had an $\mathrm{EC}_{50}<1$ $\mu \mathrm{g} / \mathrm{ml}$ (Table 1 ). The IR isolates were still sensitive to tebuconazole and benomyl (Table 1). The $\mathrm{EC}_{50}$ to iprodione correlated significantly with the $\mathrm{EC}_{50}$ to vinclozolin
( $r=0.866, P=0.0003$ ), but not with the $\mathrm{EC}_{50}$ to tebuconazole or benomyl.

Osmotic sensitivity. All IR isolates grew slower on APDA dishes amended with $\mathrm{NaCl}$ than their wild-type parent counterparts (IS isolates; Fig. 2). Most IR isolates reached the maximum inhibition of mycelium growth at about $2 \% \mathrm{NaCl}$, whereas a higher concentration of $\mathrm{NaCl}$ was needed to inhibit the

Table 1. Values for effective concentration $\left(\mathrm{EC}_{50}\right)$ of iprodione, vinclozolin, tebuconazole, and benomyl to inhibit $50 \%$ of mycelial growth of Botryosphaeria dothidea isolates from California pistachio

\begin{tabular}{lcccc}
\hline & \multicolumn{4}{c}{$\mathbf{E C}_{\mathbf{5 0}}(\boldsymbol{\mu g} / \mathbf{m l})$} \\
\cline { 2 - 5 } Isolate $^{\mathbf{z}}$ & Iprodione & Vinclozolin & Tebuconazole & Benomyl \\
\hline 1S & 0.730 & 0.224 & 0.081 & 0.056 \\
3S & 0.568 & 0.220 & 0.057 & 0.053 \\
4S & 0.606 & 0.205 & 0.038 & 0.038 \\
9S & 0.502 & 0.191 & 0.142 & 0.075 \\
11S & 0.594 & 0.168 & 0.066 & 0.086 \\
15S & 0.541 & 0.230 & 0.021 & 0.071 \\
1R & 43.544 & $>50$ & 0.049 & 0.047 \\
3R & 78.215 & $>50$ & 0.058 & 0.039 \\
4R & 71.411 & $>50$ & 0.055 & 0.052 \\
9R & 34.169 & $>50$ & 0.115 & 0.054 \\
11R & 25.831 & $>50$ & 0.191 & 0.078 \\
15R & 84.617 & 0.045 & 0.039 \\
\hline
\end{tabular}

${ }^{\mathrm{z}}$ Isolates 1R, 3R, 4R, 9R, 11R, and 15R were derived from wild-type isolates 1S, 3S, 4S, 9S, 11S and $15 \mathrm{~S}$, respectively, after three generations of selection on media amended with iprodione.
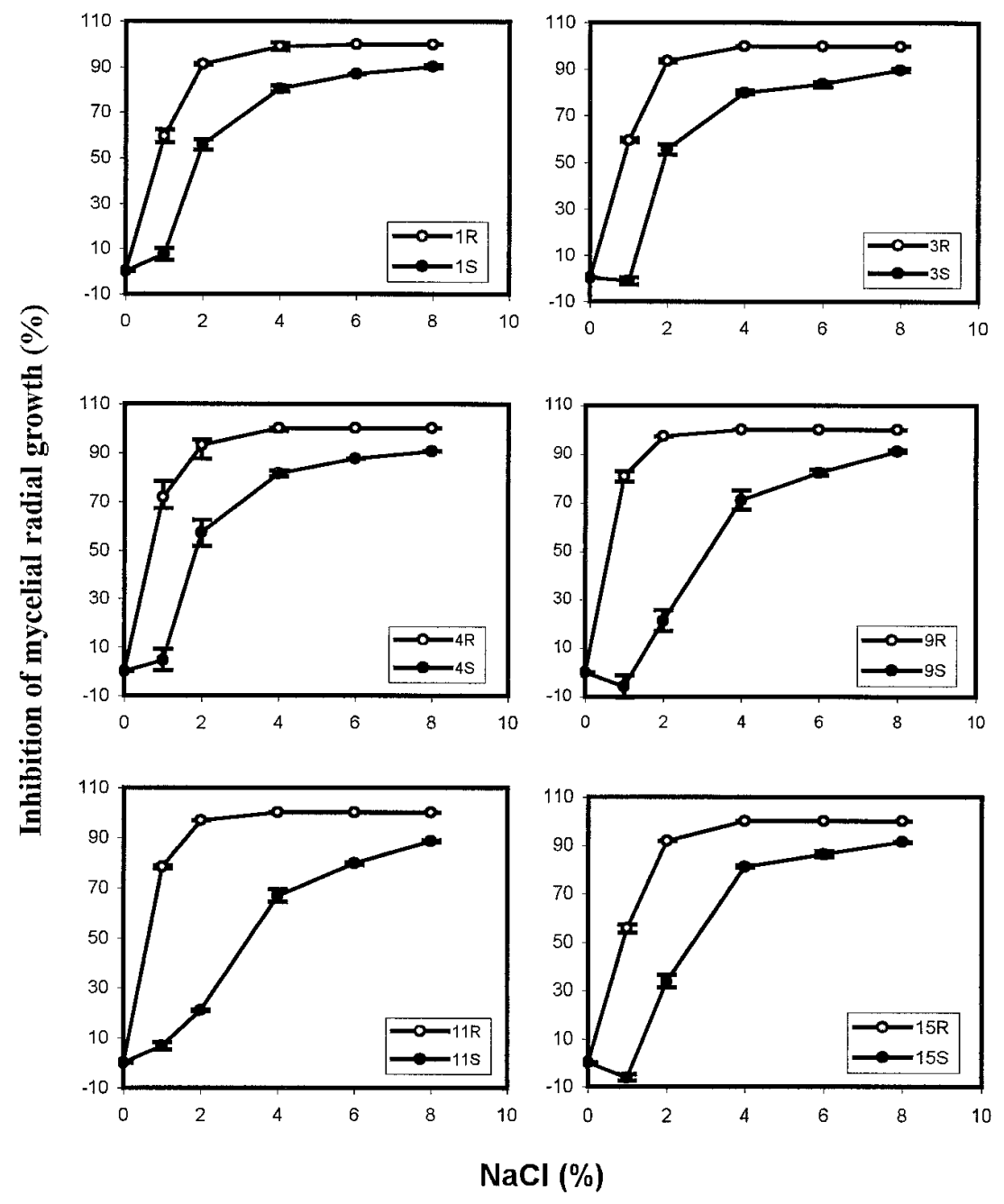

Fig. 2. Osmotic sensitivity of Botryosphaeria dothidea isolates from pistachio. The inhibition of mycelial growth on acidified potato dextrose agar media amended with different $\mathrm{NaCl}$ concentrations was tested for six iprodione-sensitive isolates $(\mathbf{O})$ and six iprodione-resistant isolates $(\bigcirc)$. Bars denote standard error. 
Table 2. Values for effective concentration $\left(\mathrm{EC}_{50}\right)$ of iprodione to inhibit $50 \%$ of mycelial growth of iprodione-resistant isolates of Botryosphaeria dothidea in different generations following mycelial propagation in greenhouse inoculation tests

\begin{tabular}{lcccccc}
\hline & \multicolumn{6}{c}{$\mathbf{E C}_{\mathbf{5 0}}(\boldsymbol{\mu g} / \mathbf{m l})^{\mathbf{z}}$} \\
\cline { 2 - 7 } Generation & $\mathbf{1 R}$ & $\mathbf{3 R}$ & $\mathbf{4 R}$ & $\mathbf{9 R}$ & $\mathbf{1 1 R}$ & $\mathbf{1 5 R}$ \\
\hline 0 & $43.544 \mathrm{a}$ & $78.215 \mathrm{a}$ & $71.411 \mathrm{a}$ & $34.169 \mathrm{a}$ & $25.831 \mathrm{a}$ & $84.617 \mathrm{a}$ \\
1 & $42.299 \mathrm{a}$ & $78.539 \mathrm{a}$ & $71.456 \mathrm{a}$ & $19.622 . \mathrm{b}$ & $11.292 \mathrm{~b}$ & $76.804 \mathrm{a}$ \\
2 & $40.325 \mathrm{a}$ & $57.530 \mathrm{~b}$ & NA & $17.610 \mathrm{~b}$ & $10.245 \mathrm{c}$ & $68.364 \mathrm{ab}$ \\
3 & $42.110 \mathrm{a}$ & $42.004 \mathrm{c}$ & $75.359 \mathrm{a}$ & $10.344 \mathrm{c}$ & $5.156 \mathrm{~d}$ & $56.289 \mathrm{bc}$ \\
4 & $24.194 \mathrm{~b}$ & $24.152 \mathrm{~d}$ & $45.956 \mathrm{~b}$ & $6.650 \mathrm{c}$ & $2.3186 \mathrm{e}$ & $45.348 \mathrm{c}$ \\
\hline
\end{tabular}

${ }^{z}$ Values in columns followed by the same letter are not significantly different according to least significant difference of SAS test at $P=0.05$. NA $=$ stock culture of second generation for isolate $4 \mathrm{R}$ was contaminated.

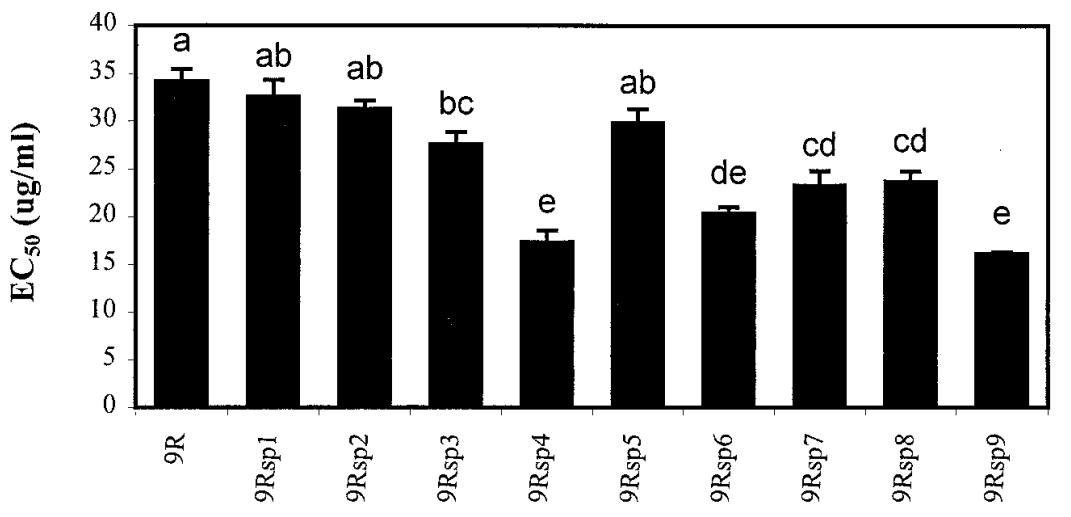

Isolate of $B$. dothidea

Fig. 3. Comparisons of effective concentration $\left(\mathrm{EC}_{50}\right)$ of iprodione to inhibit $50 \%$ of mycelial growth between an iprodione-resistant isolate (9R) of Botryosphaeria dothidea and nine single-conidial isolates derived from isolate $9 \mathrm{R}$. Each bar represents a mean of two experiments. Comparisons were conducted with least significant difference of SAS and values with the same letter are not significantly different at $P=0.05$.

mycelium growth of the IS isolates (Fig. 2).

Resistance stability of IR isolates. After successive inoculation of pistachio leaves with each IR isolate, the $\mathrm{EC}_{50}$ values for the fourth generation of all IR isolates were significantly lower than those for the first generation (Table 2). Comparisons between the $9 \mathrm{R}$ isolate and the nine single-conidial isolates derived from the 9R isolate demonstrated that the $\mathrm{EC}_{50}$ values for the six single-conidial isolates were significantly lower $(P=0.05)$ than that for 9R, but three others showed no difference at $P=0.05$ (Fig. 3).

Efficacy of iprodione in controlling disease caused by IR and IS isolates and the LR isolate. Laboratory tests demonstrated that, when iprodione was not applied, IR and IS isolates caused similar lesion lengths (no statistical difference) on detached pistachio leaves (Fig. 4A). However, when iprodione at $500 \mu \mathrm{g} / \mathrm{ml}$ was applied, all six IS isolates caused significantly smaller lesions than all six IR isolates (Fig. 4B). The efficacy of iprodione in controlling disease caused by any of the IR isolates was also significantly lower than that caused by the IS isolates (Fig. 4C).

Greenhouse tests also showed that, when mixtures of the six IR or six IS isolates naturally occurring IR isolates of $B$. dothidea are rare to absent in California pistachio orchards, especially in those orchards without a prior history of iprodione usage.

The development of fungal resistance to iprodione has been well documented $(4,10,15,22,25)$. The results presented here for California pistachio isolates of $B$. dothidea also concur with these findings. Naturally occurring IR $B$. dothidea isolates are not commonly encountered in the field; however, this fungal species also easily develops resistance in culture under iprodione selection pressure. When subjected to media amended with iprodione, six out of nine tested isolates developed resistance readily. The $\mathrm{EC}_{50}$ values for these isolates to iprodione were $>25 \mu \mathrm{g} / \mathrm{ml}$, whereas the $\mathrm{EC}_{50}$ for the original wild-type counterparts were $<1 \mu \mathrm{g} / \mathrm{ml}$.

Altered colony morphology of IR fungi growing on fungicide-amended medium has been reported for some fungal plant pathogens. For instances, cultures of Alternaria alternata pv. citri, when grown on media amended with iprodione, readily develop resistance sectors (24). In this study of $B$. dothidea, however, after a period of incubation on iprodione-amended media, some isolates began to grow at varying rates. Although colonies were sometimes irregular in appearance, particularly in their colony margins, it appeared, in general, that the whole colony grew rather than individual sectors. Similar findings were reported for $S$. minor (10). Additionally, in vitro-derived IR isolates of $B$. dothidea showed an increase in osmotic sensitivity (Fig. 2). Similar findings were also reported for laboratory and field dicarboximide-resistant isolates of $B$. cinerea $(1,7,12)$, Aspergillus nidulans (1), Penicillium expansum (1), and Neurospora crassa (9). The osmotic sensitivity may be associated with a change in cell wall composition, thereby causing a decrease in fitness of the resistant isolates in the field $(6,9)$.

The fitness of dicarboximide-resistant fungal isolates, especially those induced in vitro, vary significantly (25). For instance, some dicarboximide-resistant fungal isolates have been reported to show lower fitness (i.e., virulence) than their wild-type counterparts $(5,8,14,22,26)$. However, high fitness in fungicide-resistant isolates has also been reported $(2,3,8,14)$. In this study, the $B$. dothidea isolate L21, a naturally occurring iprodione LR isolate, showed low virulence to pistachio. Conversely, laboratory-induced IR isolates of $B$. dothidea retained the original high virulence levels associated with wild-type IS isolates. Thus, although fungicide resistance levels in the IR isolates of $B$. dothidea did decline following successive propagation on pistachio leaves in the absence of fungicide (Table 2), high levels of virulence to pistachio were maintained for both sets of isolates. 



Fig. 4. Comparisons in lesion length between iprodione-sensitive ( $\square$ ) and iprodione-resistant ( $\square$ ) isolates of Botryosphaeria dothidea. Data were collected from pistachio leaves A, not sprayed with iprodione, B, sprayed with iprodione at $500 \mu \mathrm{g} / \mathrm{ml}$, and C, comparisons of iprodione efficacy in controlling Botryosphaeria panicle and shoot blight among isolates. Each bar represents a mean of two experiments; bars in a graph with the same letter are not significantly different at $P=0.05$.

The efficacy of iprodione in controlling IR fungal isolates can be variable (25). In vitro-derived (3) and in vivo-derived (22) fungicide-resistant isolates of $S$. minor from peanut were virulent, but control by dicarboximides in the field was equal to that achieved against sensitive isolates. Conversely, iprodione failed to reduce lettuce drop caused by a virulent IR isolate of $S$. minor, but significantly reduced lettuce drop incited by wild-type sensitive isolates (10). In the present study, iprodione at 500 $\mu \mathrm{g} / \mathrm{ml}$ showed good efficacy in controlling pistachio Botryosphaeria blight caused by the LR isolate L21 and by the wild-type IS isolates. In contrast, iprodione at the same concentration had a little effect in controlling disease caused by IR isolates both in laboratory and greenhouse tests (Fig. 5).

Isolates of $B$. dothidea readily developed resistance to iprodione on media amended with this fungicide, indicating that this fungus has a great propensity to overcome sensitivity to this fungicide. Applications of iprodione at up to $500 \mu \mathrm{g} / \mathrm{ml}$ failed to control the disease by these IR isolates in the greenhouse tests. Therefore, although IR isolates are rarely encountered in the fields, $B$. dothidea isolates may develop substantial tolerances to this fungicide fairly quickly, over only several generations. The retention of full virulence in these IR isolates of $B$. dothidea should pose a significant threat to commercial plantings of California pistachio. Thus, an appropriate strategy to control Botryosphaeria panicle and shoot blight in California would be a series of applications, which involve the sequential rotation of fungicides without cross-resistance. For example, tebuconazole shows good efficacy in controlling this disease (18) and does not display cross-resistance with iprodione (Table 1). Furthermore, iprodione resistance levels in the IR isolates of $B$. dothidea did decline following successive propagation on pistachio leaves in the absence of this fungicide. Therefore, alternating applications of iprodione, tebuconazole, and benomyl may delay resistance development of iprodione in California pistachio orchards.
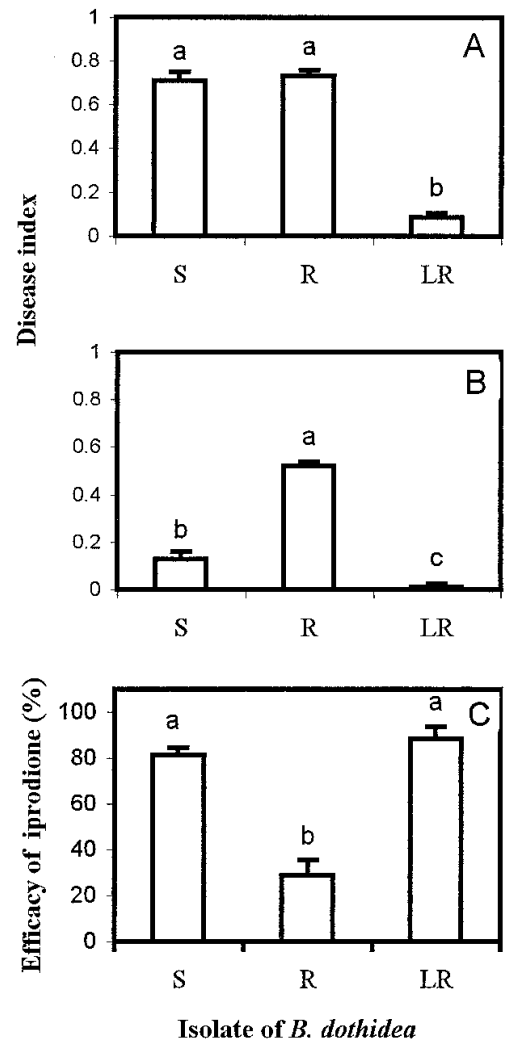

Fig. 5. Comparisons in disease index between iprodione-sensitive isolates (S), iprodione-resistant isolates (R), and an isolate with low iprodione resistance (LR) of Botryosphaeria dothidea $\mathbf{A}$, without iprodione application, $\mathbf{B}$, with iprodione application at $500 \mu \mathrm{g} / \mathrm{ml}$, and $\mathbf{C}$, comparisons of iprodione efficacy in controlling Botryosphaeria panicle and shoot blight among isolates. Each bar represents a mean of two experiments; bars in a graph with the same letter are not significantly different at $P=0.05$.

\section{ACKNOWLEDGMENTS}

We thank E. W. A. Boehm for critically reading this manuscript, and D. P. Morgan and D. Felts for collection of some isolates.

\section{LITERATURE CITED}

1. Beever, R. E. 1983. Osmotic sensitivity of fungal variants resistant to dicarboximide fungicides. Trans. Br. Mycol. Soc. 80:327331 .

2. Biggs, A. R. 1994. Mycelial growth, sporulation, and virulence to apple fruit of Alternaria alternara isolates resistance to iprodione. Plant Dis. 78:732-735.

3. Brenneman, T. B., Phipps, P. M., and Stipes, R. J. 1987. Sclerotinia blight of peanut: relationship between in vitro resistance and field efficacy of dicarboximide fungicides. Phytopathology 77:1028-1032.

4. Chastagner, G. A., and Vassey, W. E. 1982. Occurrence of iprodione-tolerant Fusarium nivale under field conditions. Plant Dis. 66:112-114.

5. Detweiler, A. R., Vargas, J. M., and Danneberger, T. K. 1983. Resistance of Sclerotinia homoeocarpa to iprodione and benomyl. Plant Dis. 67:627-630.

6. Ellis, S. W., Grindle, M., and Lewis, D. H. 1991. Effect of osmotic stress on yield and polyol content of dicarboximide-sensitive and -resistant strains of Neurospora crassa. Mycol. Res. 95:457-464.

7. Faretra, F., and Pollastro, S. 1991. Genetic 
basis of resistance to benzimidazole and dicarboximide fungicides in Botryostinia fuckeliana (Botrytis cinerea). Mycol. Res. 95:943951.

8. Gouot, J. M. 1988. Characteristics and population dynamics of Botrytis cinerea and other pathogens resistance to dicarboximide. Pages 53-55 in: Fungicide Resistance in North America. C. J. Delp, ed. American Phytopathological Society, St. Paul, MN.

9. Grindle, M., and Temple, W. 1985. Sporulation and osmotic sensitivity of dicarboximideresistant mutants of Neurospora crassa. Trans. Br. Mycol. Soc. 84:369-372.

10. Hubbard, J. C., Subbarao, K. V., and Koike, S. T. 1997. Development and significance of dicarboximide resistance in Sclerotinia minor isolates from commercial lettuce fields in California. Plant Dis. 81:148-153.

11. Hunter, T., Brent, K. J., Carter, G. A., and Hutcheon, J. A. 1987. Effects of fungicide spray regimes on incidence of dicarboximide resistance in gray mould (Botrytis cinerea) on strawberry plats. Ann. Appl. Biol. 110:515525 .

12. Johnson, K. B., Sawyer, L. T., and Powelson, M. L. 1994. Frequency of benzimidazole- and dicarboximide-resistant strains of Botrytis cinerea in western Oregon small fruit and snap bean plantings. Plant Dis. 78:572-577.

13. Locke, T., and Fletcher, J. T. 1988. Incidence of benomyl and iprodione resistance in isolates of Botrytis cinerea in tomato crops in England and Wales in 1986. Plant Pathol. 37:384-384.
14. Lorenz, G. 1988. Dicarboximide fungicide: History of resistance development and monitoring methods. Pages 45-51 in: Fungicide Resistance in North America. C. J. Delp, ed. American Phytopathological Society, St. Paul, $\mathrm{MN}$.

15. McPhee, W. J. 1980. Some characteristics of Alternaria alternata strains resistant to iprodione. Plant Dis. 64:847-849.

16. Michailides, T. J., and Morgan, D. P. 1996. Chemical control of Alternaria late blight and Botryosphaeria panicle and shoot blight of pistachio in California. Pages 72-76 in : Calif. Pistachio Ind. Annu. Rep. Crop Year 199596.

17. Michailides, T. J., Morgan, D. P., and Felts, D. 1997. Control of Botryosphaeria panicle and shoot blight of pistachio with pruning and fungicides. Pages 69-72 in: Calif. Pistachio Ind. Annu. Rep. Crop Year 1996-97.

18. Michailides, T. J., Morgan, D. P., Felts, D., Krueger, W., and Weinberger, G. 1999. Chemical control of Botryosphaeria blight of California pistachios in 1998. Pages 83-84 in: Calif. Pistachio Ind. Annu. Rep. Crop Year 1998-99.

19. Michailides, T. J., Morgan, P. D., Felts, D., and Ribiero, B. 1997. Disease monitoring, prediction and spread of Botryosphearia dothidea in central California pistachio orchards. Pages 73-81 in: Calif. Pistachio Ind. Annu. Rep. Crop Year 1996-97.

20. Michailides, T. J., Yuan, C., Morgan, P. D., Necker, E., and Krueger, W. 1999. Latent infection of pistachio fruits and leaves by $\mathrm{Bo}$ - tryosphaeria dothidea. Pages 215-223 in: Calif. Pistachio Comm. 1998-99 Prod. Res. Rep.

21. Pak, H. A., Beever, R. E., and Laracy, E. P 1990. Population dynamics of dicarboximideresistant strains of Botrytis cinerea on grapevine in New Zealand. Plant Pathol. 39:501509.

22. Smith, F. D., Phipps, P. M., and Stipes, R. J 1991. Agar plate, soil plate and field evaluation of fluazinam and other fungicides for control of Sclerotinia minor on peanut. Plant Dis. 75:1138-1143.

23. Smith, F. D., Phipps, P. M., Stipes, R. J., and Brenneman, T. B. 1995. Significance of insensitivity of Sclerotinia minor to iprodione in control of Sclerotinia blight of peanut. Plant Dis. 79:517-523.

24. Solel, Z., Timmer, L. W., and Kimchi, M. 1996. Iprodione resistance of Alternaria alternata pv. citri from Minneola tangelo in Israel and Florida. Plant Dis. 80:291-293

25. Staub, T. 1991. Fungicide resistance: Practical experience with anti-resistance strategies and the role of integrated use. Annu. Rev. Phytopathol. 29:421-442.

26. Vali, R. J., and Moorman G. W. 1992. Influence of selected fungicide regimes on frequency of dicarboximide-resistant and dicarboximide-sensitive strains of Botrytis cinerea. Plant Dis. 76:919-924.

27. Yunis, H., and Elad, Y. 1989. Survival of dicarboximide-resistant strains of Botrytis cinerea in plant debris summer in Israel. Phytoparasitica 17:13-21. 